\title{
Signaling Peptides in Plants
}

Sarieh Ghorbani ${ }^{1,2}$, Ana Fernandez ${ }^{1,2}$, Pierre Hilson ${ }^{3,4}$ and Tom Beeckman ${ }^{1,2^{*}}$

${ }^{1}$ Department of Plant Systems Biology, VIB, B-9052 Ghent, Belgium

${ }^{2}$ Department of Plant Biotechnology and Bioinformatics, Ghent University, B-9052 Ghent, Belgium

3INRA, UMR1318, Institut Jean-Pierre Bourgin, RD10, F-78000 Versailles, France

${ }^{4}$ AgroParisTech, Institut Jean-Pierre Bourgin, RD10, F-78000 Versailles, France

*Corresponding author: Tom Beeckman, Department of Plant Systems Biology, VIB, B-9052 Ghent, Belgium, Tel: 32-0-93313830; E-mail: tobee@psb.vib-ugent.be Rec date: May 03, 2014; Acc date: Jun 16, 2014; Pub date: Jun 18, 2014

Copyright: $\odot 2014$ Ghorbani S, et al. This is an open-access article distributed under the terms of the Creative Commons Attribution License, which permits unrestricted use, distribution, and reproduction in any medium, provided the original author and source are credited.

\begin{abstract}
In multicellular organisms, growth and development need to be precisely coordinated and are strongly relying on positional information. Positional control is achieved through exchanges of molecular messages between cells and tissues by means of cell-to-cell communication mechanisms. Especially in plants, accurate and well-controlled cell-to-cell communication networks are essential because of the complete absence of cell mobility and the presence of rigid cell walls. For many years, phytohormones were thought to be the main messengers exchanged between cells. Nevertheless, identification of systemin as the first plant signaling peptide in tomato hinted that peptide hormones were acting in plants as they were in animals. During the last decade, our knowledge of plant signaling peptides has progressed considerably and a number of signaling peptide families have been discovered and partially characterized. Here, we provide an overview of the current knowledge in signaling peptides in the model species Arabidopsis thaliana and discuss their proposed functions during plant growth and development.
\end{abstract}

Keywords: Arabidopsis thaliana; Cell-to-cell communications; Signaling peptides

\section{Introduction}

Response to developmental cues and environmental stimuli in multicellular organisms is highly dependent on cell-to-cell communication. For many years, the so-called classical phytohormones - auxin, cytokinin, abscisic acid, gibberellin and ethylene - were thought to be the main players of intercellular communication in plants. Later on, several other molecules, including brassinosteroids, jasmonate, salicylic acid and strigolactones, have been added to the list of plant growth regulators $[1,2]$. However, it remained puzzling that such a relatively small group of molecules could coordinate multiple and very diverse cellular responses. Research over the last decade made clear that, besides the plant hormones, other molecules are important players in cell-to-cell communication networks, including signaling peptides (also called "peptide hormones" or "secreted peptides"), small RNAs and transcription factors $[1,3,4]$. Secreted peptides are now fully recognized in plants as molecular messengers because of their involvement in key developmental processes such as meristem maintenance, organ abscission, cell elongation, cell proliferation and differentiation, gravitropism and defense against biotic aggressors [5-10]. Here, we will describe recent advances made in the characterization of signaling peptide function during plant development including a reflection on some recent developments in signaling peptide identification strategies.

\section{Structural Characteristics and Posttranslational Modifications of Signaling Peptides}

Peptides are generally defined as small proteins containing 50 or fewer amino acids in their mature form [4]. Systemin was the first plant signaling peptide identified and was shown to be involved in systemic response to wounding in tomato [11]. Following the discovery of systemin, several signaling peptides have been characterized in plants, especially in Arabidopsis (Table 1). Nevertheless, considering the myriad of signaling peptides in mammals [12], it is likely that many more still remain to be identified.

\begin{tabular}{|c|c|c|c|c|c|c|}
\hline Peptide family & Mature peptide & $\begin{array}{l}\text { Gene } \\
\text { family in } \\
\text { Arabidopsis }\end{array}$ & $\begin{array}{l}\text { Conserved } \\
\text { motif }\end{array}$ & Receptor & Function & References \\
\hline $\begin{array}{l}\text { Clavata3/Endosperm } \\
\text { Surrounding Region (ESR)- } \\
\text { Related }\end{array}$ & CLV3/CLE & 32 & $\begin{array}{l}\text { CLE or mCLV3, } \\
12-14 \text { AA }\end{array}$ & $\begin{array}{l}\text { CLV1, BAM1, } \\
\text { CLV2, RPK2, } \\
\text { ACR4 }\end{array}$ & $\begin{array}{l}\text { Stimulates organogenesis } \\
\text { and inhibits } \\
\text { meristematic growth; } \\
\text { can stimulate vascular } \\
\text { development }\end{array}$ & $\begin{array}{l}{[5,28,41,58,98} \\
-101]\end{array}$ \\
\hline
\end{tabular}


Citation: Ghorbani S, Fernandez A, Hilson P, Beeckman T (2014) Signaling Peptides in Plants. Cell Dev Biol 3: 141. doi: 10.4172/2168-9296.1000141

Page 2 of 11

\begin{tabular}{|c|c|c|c|c|c|c|}
\hline C-Terminally Encoded Peptide & CEP & 15 & CEP1, 14 AA & - & Inhibits root growth & {$[23,29]$} \\
\hline Embryo Surrounding Factor1 & ESF1 & 3 & ESF1, 68 AA & SSP & $\begin{array}{l}\text { Early embryo patterning in } \\
\text { flowering plants }\end{array}$ & [94] \\
\hline $\begin{array}{l}\text { Epidermal Patterning Factor } / 1 \\
\text { EPF-Like }\end{array}$ & EPF & 11 & - & $\begin{array}{l}\text { TMM, ER, } \\
\text { ERL1, ERL2 }\end{array}$ & $\begin{array}{l}\text { Promotes epidermal cell } \\
\text { division leading to } \\
\text { guard cell (stomata) } \\
\text { formation }\end{array}$ & {$[18,19,72]$} \\
\hline $\begin{array}{l}\text { Golven/Root Growth Factor/ } \\
\text { CLE-Like }\end{array}$ & GLV/RGF/CLEL & 11 & $13-18 \mathrm{AA}$ & - & $\begin{array}{l}\text { Maintain root stem cell } \\
\text { Niche, gravitropic response, } \\
\text { lateral root and root hair } \\
\text { development. }\end{array}$ & {$[9,10,22,46]$} \\
\hline $\begin{array}{l}\text { Inflorescence Deficient in } \\
\text { Abscission and IDA-Like }\end{array}$ & IDA /IDL & 6 & EPIP & HAE, HSL & $\begin{array}{l}\text { Inhibits floral abscission } \\
\text { Lateral root primordium } \\
\text { development, cell separation }\end{array}$ & {$[7,69,71]$} \\
\hline Phytosulfokine & PSK & 6 & PSK-a, 5 AA & PSKR1 & $\begin{array}{l}\text { Promotes cell proliferation } \\
\text { and longevity, root and } \\
\text { hypocotyl } \\
\text { elongation }\end{array}$ & {$[24,86-88,102]$} \\
\hline Plant Natriuretic Peptide & PNP & 2 & - & - & $\begin{array}{l}\text { Extracellular, cell } \\
\text { expansion, water/ion } \\
\text { movement, stomatal } \\
\text { opening, inhibits } \\
\text { ABA-induced stomatal } \\
\text { closure }\end{array}$ & [103-109] \\
\hline $\begin{array}{lcc}\text { Plant } & \text { Peptide } & \text { Containing } \\
\text { Sulfated Tyrosine } & \end{array}$ & PSY & 3 & PSY1, 18 AA & PSYR1 & $\begin{array}{l}\text { Promotes cellular } \\
\text { expansion and } \\
\text { proliferation, } \\
\text { upregulated by } \\
\text { wounding }\end{array}$ & [8] \\
\hline Polaris & PLS & 1 & $36 \mathrm{AA}$ & - & $\begin{array}{l}\text { Required for root } \\
\text { elongation, lateral root } \\
\text { formation, leaf vascular } \\
\text { patterning }\end{array}$ & {$[97,110]$} \\
\hline Propep & AtPep & 7 & Pep1, 23 AA & Pep1R & $\begin{array}{l}\text { Promotes innate immune } \\
\text { responses }\{\text { a danger } \\
\text { signal\} }\end{array}$ & [111-114] \\
\hline $\begin{array}{l}\text { Rapid Alkalinization Factor And } \\
\text { RALF-Like }\end{array}$ & RALF/RALFL & 39 & $\begin{array}{l}\text { RALF, 25-30 } \\
\text { AA }\end{array}$ & FERONIA & $\begin{array}{l}\text { Associated with danger } \\
\text { signals, affects } \\
\text { growth-inhibits root } \\
\text { growth }\end{array}$ & {$[6,14,90,115]$} \\
\hline Rot Four Like/ Devil & RTFL/DVL & 24 & Not processed & - & $\begin{array}{l}\text { Polarity, cell porolifration, leaf } \\
\text { development }\end{array}$ & [116-118] \\
\hline $\begin{array}{l}\text { S_Locus Cysteine_Rich } \\
\text { Protein/SCR_Like }\end{array}$ & SCR/SCRL & 28 & Not processed & SRK & Prevents self-fertilization & {$[15,119]$} \\
\hline Systemin & - & Not present & $18 \mathrm{AA}$ & SR160 & Systemin defense response & [11] \\
\hline Tapetum Determinant & TPD & 2 & TPD & EMS1 & Anther development & {$[42,120]$} \\
\hline
\end{tabular}




\begin{tabular}{|l|l|l|l|l|l|l|}
\hline & & & & & Promoting tapetum formation & \\
\hline
\end{tabular}

Table 1: Plant peptide signaling molecules identified so far

Based on structural characteristics, signaling peptides are divided into two distinct groups [13]. Group I consists of cysteine-rich peptides in which intramolecular disulfide bonds determine the threedimensional structure of the mature protein. Peptides in this group may or may not undergo proteolytic processing. Mature cysteine-rich peptides are generally longer than 20 amino acids [14]. Secreted peptides belonging to this class include the S-locus Cys-rich or S-locus protein 11 (SCR/SP11) [15,16], LURE [17], RAPID ALKALINIZATION FACTORs (RALFs) [6] and EPIDERMAL PATTERNING FACTORs (EPFs) [18,19] including STOMAGEN [20].

Group II includes cysteine-poor peptides, also called "small posttranslationally modified peptides". In contrast to the aforementioned group, this class is characterized by the small size of the mature peptide $(<20$ amino acids $)$ always resulting from proteolytic processing, and the presence of a C-terminal conserved motif that often carries proline residues and posttranslational modifications. Like cysteine-rich peptides, they are generally encoded by multiple paralogous genes. Most signaling peptides characterized so far in plants belong to this class. Small posttranslationally modified peptides share a common tripartite structure: (i) a signal peptide at the $\mathrm{N}$-terminal region, (ii) a C-terminal region that is usually conserved among different members of the family and corresponds to the mature peptide and (iii) a variable segment that links the two terminal domains (Figure 1).

\section{\begin{tabular}{|l|l|l|}
\hline SP & Variable region & $\mathrm{CM}$ \\
\hline
\end{tabular}}

Figure 1: Structure of Group II signaling prepropeptides. SP, signal peptide recognized and cleaved upon secretion. CM, conserved motif yielding the mature peptide.

In contrast to the majority of the peptides, which are produced by the cleavage of larger precursors, EARLY NODULIN40 (ENOD40) peptides are encoded as such [21]. Interestingly, it has been shown that several signaling precursors contain multiple copies of the C-terminal motif or exhibit a second conserved one in the variable segment $[22,23]$. However the functional consequences of these peculiar arrangements remain unknown.

In plants, the C-terminal region of small posttranslationally modified peptides often carries one or more of three types of posttranslational modifications: tyrosine sulfation [8-10,24], which is catalyzed by the plant-specific TYROSYL PROTEIN SULFOTRANSFERASE (TPST) [25], proline hydroxylation $[8,9,26-30]$ that is mediated by PROLYL 4 -HYDROXYLASE $(\mathrm{P} 4 \mathrm{H})$ [31] and hydroxyproline arabinosylation. Hydroxyproline arabinosylation $[8,30]$ is a plant-specific posttranslational modification [32] and, only recently, three HYDROXYPROLINE OARABINOSYLTRANSFERASE (HPAT) enzymes have been discovered in Arabidopsis [33]. Posttranslational modifications contribute to the native structure, and may enhance the binding capacity of the peptide ligand to its receptor. In some studies, the lack of posttranslational modification has been shown to reduce the peptide activity $[13,34,35]$. Posttranslational modifications are thus, probably necessary for full bioactivity and downstream signaling $[13,34,35]$.

The mechanisms by which plant-secreted peptides are produced are not well understood, but are thought to be somewhat similar to the maturation process of their mammalian counterparts. In general, signaling peptides are translated as large precursors (so called prepropeptides) followed by one or more posttranslational modifications and/or proteolytic processing. Based on what is known from the study of animal neuropeptides, the maturation of signaling peptides is assumed to start by the co-translational removal of the N-terminal signal peptide by Signal Peptide Peptidases (SPPs) in the endoplasmic reticulum to yield the propeptide $[12,13,36]$. The cleavage site in the precursor can be predicted with a high degree of accuracy [37]. The resulting propeptide is likely to be directed through the Golgi apparatus and, together with processing proteases, loaded into newly formed secretory vesicles. Later on, as the vesicle matures, proteolytic processing occurs with removal of the variable region and release of the mature peptide contained in the C-terminal region (some cysteinerich peptides do not require this proteolysis step). Finally, mature peptides will be released to the extracellular space and will bind to the cognate receptor(s) in the plasma membrane of neighboring cells, or more distant cells if the peptides are somehow channeled away, where they trigger a signaling pathway that initiates specific physiological responses [12].

Although the overall pathways involved in the production of signaling peptides in plants and animals are most probably similar, some details in these processes are still uncharacterized. Plant peptides are generally small and not functional when associated with large tags. Their intracellular localization has thus not yet been achieved, and in plants, the detection of peptide-carrying vesicles is still pending. Furthermore, in mammals, neuropeptides and peptide hormones are produced by specialized cells, such as neurons and neuroendocrine cells, and in certain cases stored in mature vesicles releasing the peptide signal when triggered by a stimulus. In plants, peptide production does not seem to be confined to certain cells or organs and any plant cell type appears to be able to deliver a peptide signal. Also, it is unclear whether plant signaling peptides are pre-packed and stored, or synthesized on demand. Only future insights will tell us to what extent peptide production and release have diverged between vertebrates and higher plants.

Membrane-localized receptors function as master switches of complex intracellular signaling networks. Receptors are activated upon binding of their ligand, often through autophosphorylation. Activated receptors will, in turn, phosphorylate downstream targets, which might result in a direct response and/or a phosphorylation cascade, including mitogen-activated protein (MAP)-kinases, and eventually lead to transcriptional regulation of specific genes $[12,13,36,38]$. 


\section{Tools to identify new small secreted peptides}

A bottleneck in the functional study of signaling peptides in plant growth and development has been the identification of the encoding genes. Genome sequencing of different plant species has led to the prediction and identification of a number of signaling molecules. However, because the precursors are rarely more than 120 amino acids long, genes encoding small peptides tend to be overlooked in genome annotations because they are difficult to distinguish from short, random open reading frames. Additionally, the detection of mature small signaling peptides in crude plant tissue extracts is also a difficult task given their very low physiological concentration (in the nanomolar range) and the presence in large amount of other peptides derived from the degradation of abundant proteins. It is therefore likely that only a few of the total number of secreted peptides are known to date. Thus, attempts to identify new signaling peptide families in plants by various approaches are still highly valuable $[4,39,40]$. They can be classified in three main types of approaches: genetic, bioinformatic and biochemical assays.

\section{Genetics}

Forward and reverse genetic approaches have been used as tools to identify new signaling peptides. For example, the clavata3 mutants were identified because they resulted in enlarged shoot apical meristems (SAM) in a forward genetic mutant screen [41]. Thanks to similar forward genetic approaches, several other signaling peptides were identified, such as INFLORESCENCE DEFICIENT IN ABSCISSION (IDA) and TAPETUM DETERMINANT1 (TPD1) $[7,42]$. Reverse genetics in combination with bioinformatics tools resulted in the identification and characterization of the GOLVEN/ Root Growth Factor/CLE-Like (GLV/RGF/CLEL) signaling peptide family $[9,10,22]$. However genetic studies have been hampered by two major hurdles: firstly, because signaling peptide genes are small, corresponding T-DNA insertion alleles are often not available; secondly, signaling peptides are usually encoded in functionally redundant multigene families impeding forward genetic screens.

\section{Bioinformatics}

Several successful examples of the discovery of signaling peptides by means of in silico approaches have been reported. Typically, several criteria are combined to search for new signaling peptide families: (i) the presence of a signal peptide sequence that would target the propeptide to the secretory pathway (for example using the SignalP algorithm, [37], (ii) the small size of the precursors, (iii) the enrichment or lack of cysteine residues in the propeptide, and (iv) the presence of sites susceptible to posttranslational modification(s). Application of one or more of the abovementioned features for in silico genome sequence searches led to the identification of multiple plant signaling peptide families including GLV/RGF/CLEL, $C$ TERMINALLY ENCODED PEPTIDE (CEP), IDA and CLAVATA3/ ESR-RELATED (CLE) members [4,7,9,10,22,29].

Despite their usefulness, bioinformatics approaches have limitations because many small genes remain poorly annotated and homology searches may not be particularly useful for the identification of functional homologs that only share a few amino acids.

\section{Biochemical Assays}

Assays have been developed to test for the presence of bioactive compounds in crude extracts, followed by the purification of the responsible secreted peptides. For example, medium alkalinization assays led to the identification of the RAPID ALKALINIZATION FACTOR (RALF) from tobacco and Phytosulfokine (PSK) was discovered in conditioned media because it promoted the proliferation of cultured cells [6,24].

Reversely, once candidate signaling peptides have been identified via genetic or bioinformatics studies, they may be chemically synthesized and applied to plant tissues or organs to analyze their action in vivo. This strategy creates opportunities to investigate the output of the peptide signaling pathway and to complement a genetic loss-of-function. But it also suffers from several limitations: peptides may act specifically in a small concentration range or in specific locations that may not be reflected when exogenously applied. Finally, the structure of the native signal, possibly including complex posttranslational modifications, may be insufficiently characterized or difficult to copy via chemical synthesis.

We anticipated that these approaches, on their own or combined, will accelerate the discovery of novel plant signaling peptides in the near future.

\section{Signaling peptides are involved in different biological processes}

Signaling peptides have been associated to diverse developmental processes in plants, such as apical meristem maintenance (CLAVATA3 (CLV3), GLV/RGF/CLEL), defense (systemins), floral organ abscission (IDA), and stomatal patterning (EPF), among others $[4,38,43-46]$. To highlight the diverse roles of signaling peptides in various developmental processes, some examples of the function of the signaling peptide families are outlined below.

\section{CLAVATA3/ESR-Related (CLE)}

The Arabidopsis CLE peptide family was originally identified through the club-shaped fruit phenotype of some of the corresponding mutants ("clava" Latin for club) [41]. Further investigations revealed that the $C L V 3$ gene is exclusively expressed in a limited number of cells in the SAM and restrains stem cell division in the SAM [5,28,47] (Figure 2). The clv3 mutants exhibit overproliferation of stem cells, resulting in a meristem almost 1,000 fold larger than that of the wild type. Overproduction of CLV3 causes loss of stem cell activity and differentiation of the shoot meristem [48]. After binding to the leucine-rich-repeat-receptor like kinase (LRR-RLK) CLV1, the CLV3 peptide promotes the repression of the homeodomain transcription factor WUSCHEL (WUS) and, through a negative feedback loop, regulates SAM homeostasis. In this model, WUS binds directly to the CLV3 promoter and activates its transcription. The CLV3 peptide suppresses WUS expression with decreased $C L V 3$ transcription as a result, thereby reducing the number of stem cells [4,5,48-52]. 
Citation: Ghorbani S, Fernandez A, Hilson P, Beeckman T (2014) Signaling Peptides in Plants. Cell Dev Biol 3: 141. doi:

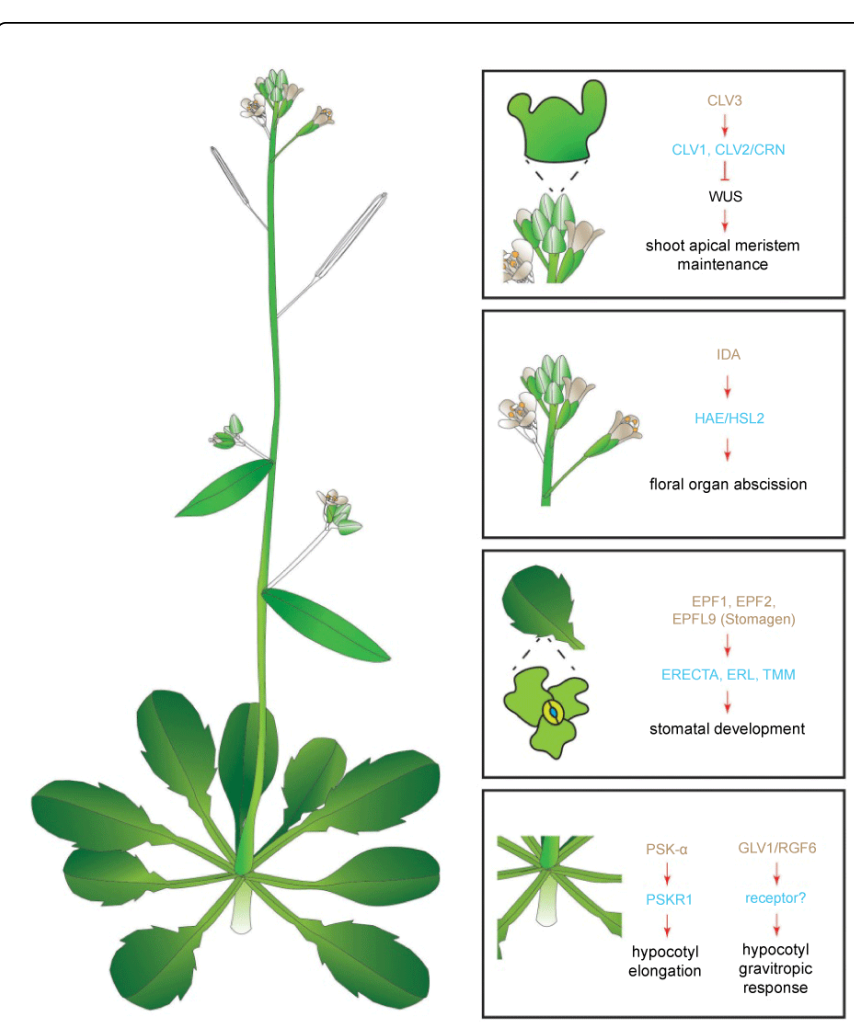

Figure 2: Peptide-mediated regulation of shoot development. Peptides are indicated in brown text and receptors in blue.

Additionally, CLV2 and CORYNE (CRN) have been shown to form a receptor complex contributing to SAM maintenance. However, CRN lacks kinase activity and no direct CLV3-CLV2/CRN binding has been demonstrated. Possibly, this receptor complex relays the CLV3 signal independently from CLV1 [53,54]. Interestingly, a clavata-like phenotype in maize has recently led to the discovery of a downstream component in this signaling pathway [55]. COMPACT PLANT2 (CT2) encodes the predicted $\alpha$-subunit $(\mathrm{Ga})$ of a heterotrimeric GTPbinding protein. The maize orthologue of $C L V 2$, FASCIATED EAR2 (FEA2), codes for a receptor without a signaling domain. FEA2 interacts with CT2 to transmit CLAVATA-dependent signals to regulate the SAM maintenance. However, genetic evidence suggested that FEA2 also signals through other pathways besides CT2/Ga [55].

A molecular mechanism controlling stem cell activity, similar to the SAM CLV-WUS pathway, has been proposed in the root apical meristem (RAM) (Figure 3). In the RAM, it is the binding of the signaling peptide CLE40 to CLV1 that would repress, together with the receptor-like kinase ARABIDOPSIS CRINKLY4 (ACR4), the expression of the transcription factor WUSCHEL-related homeobox 5 (WOX5). WOX5 controls the communication between the quiescent center (QC) and the surrounding stem cells and promotes the stem cell identity in these cells. Plants overexpressing CLE4O display a stunted primary root growth. It is thought that the CLE40-ACR4/ CLV1 signaling restrains the production of WOX5 to the QC, thereby restricting the stem cell identity to the cells in contact with the QC cells. According to this model, increased levels of CLE40 prevents WOX5 to reach the neighboring cells that ultimately lose their stem cell nature and differentiate. In cle 40 and acr 4 mutants, the inhibition is lost and the WOX5 expression domain is expanded resulting in the overproliferation of stem cells [56-58] (Figure 3).

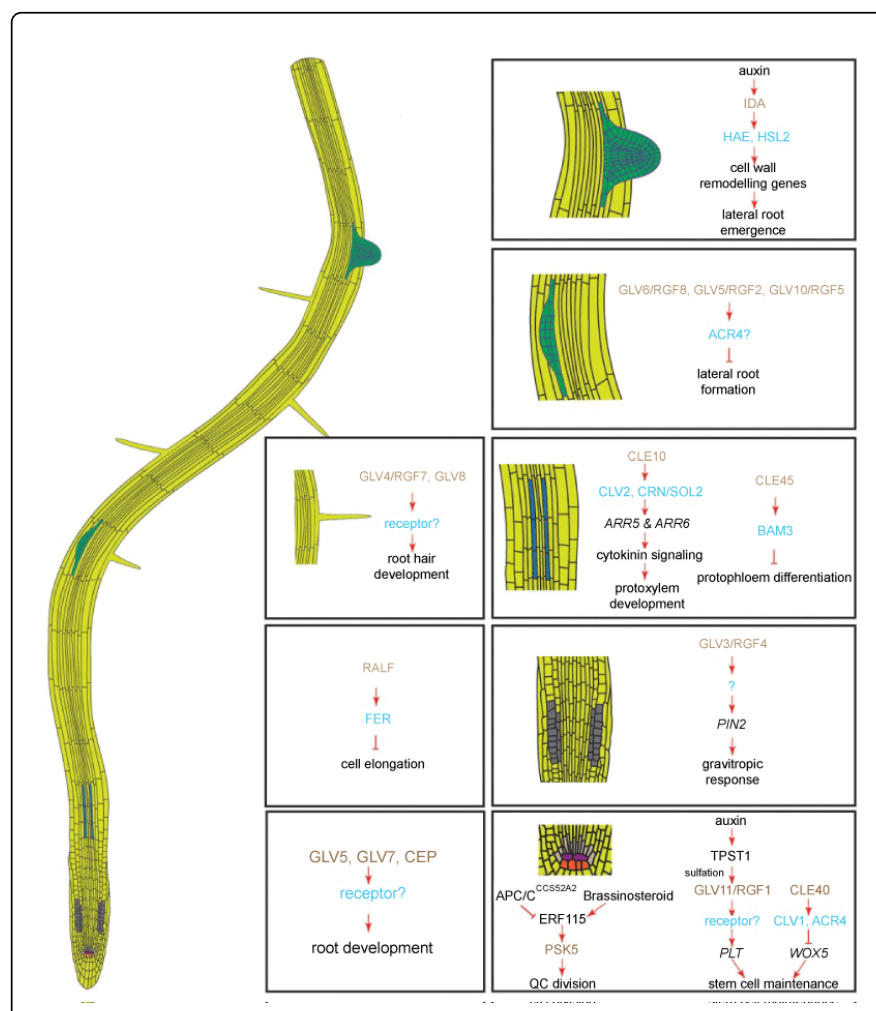

Figure 3: Peptide-mediated regulation of root development. Peptides are indicated in brown text and receptors in blue.

The role of plant hormones, transcription factors and microRNAs signals is well established in vasculature development. Recent studies have also highlighted the action of signaling peptides in this context. The TRACHEARY ELEMENT DIFFERENTIATION INHIBITORY FACTOR (TDIF) peptide stimulates procambial cell proliferation in the leaf and hypocotyl vasculature and at the same time constrains the differentiation of procambial cells into tracheary elements. TDIF was isolated first from mesophyll cell cultures of Zinnia elegans in which the tracheary element differentiation was arrested. Later investigation led to the isolation of an extracellular 12-amino acid peptide and a homology search revealed that TDIF was identical to the C-terminal motif of CLE41 and CLE44 and highly homologous to CLE42 and CLE46 in Arabidopsis [27,59]. Accordingly, cle41 and cle44 mutants show a reduced number of procambial cells and exogenous application of TDIF also increases procambial cell proliferation in Arabidopsis hypocotyls [27,60-62]. The TDIF RECEPTOR/PHLOEM INTERCALATED WITH XYLEM (TDR/PXY) gene was identified as coding for an LRR-RLK receptor potentially involved in TDIF recognition. TDR/PXY is mainly expressed in procambium and cambium cells, whereas CLE41 is transcribed in neighboring phloem cells, indicating that CLE41 must be secreted towards the procambium where it is perceived by TDR/PXY [60,62,63]. Intriguingly, another WUS-related homeobox gene, WOX4, is essential for the regulatory function of TDIF in the vascular cell fate, but not for TDIF inhibition of xylem differentiation [64,65]. The signaling peptides CLE9 and CLE10 have also been reported to be produced in the vasculature and to function in vascular development. CLE1O overexpression results in 
severe inhibition of the protoxylem formation in roots. The CLE9/ CLE10 peptides are assumed to signal through the CLV2 receptor to inhibit protoxylem formation in roots via cytokinin signaling. Accordingly, protoxylem formation is no longer inhibited by CLE9/ CLE10 peptides in Clv2 mutants, indicating a link between the CLE9/ CLE10 ligand and the CLV2 receptor in vascular development [66] (Figure 3). Another CLE peptide, CLE45, was recently reported to be involved in protophloem differentiation. Recent studies have suggested that CLE45 might interact directly or indirectly with the leucine-rich repeat receptor-like kinase BARELY ANY MERISTEM 3 (BAM3) to negatively regulate protophloem differentiation. CLE45 and $B A M 3$ are both expressed along the developing protophloem, up to the beginning of the elongation zone, and are proposed to function in the transition from proliferation to differentiation [67].

\section{Inflorescence Deficient in Abscission/ IDA-Like (IDA/ IDAL)}

Abscission is one of the developmental processes in plants that are coordinated by signaling peptides. Abscission is essential for optimal plant growth, because organs that are not necessary or functional anymore have to be removed through precise and programmed cell separation [68-70]. IDA and IDA-LIKE (IDL) signaling peptides have been shown to promote organ abscission by stimulating cell separation or by inhibiting cellular repair mechanisms [7,70] (Figure 2). The IDA and $I D L$ genes are expressed in the cell separation zone that comprises the region where the organs are detached from the plant body [70]. It is believed that they signal through the LRR-RLKs HAESA (HAE) and HAESA-LIKE2 (HSL2) [70]. The ida knockout mutants retain floral organs, whereas plants overexpressing the IDA or IDL genes exhibit premature floral organ abscission, with overproliferation of the abscission zone and, additionally, ectopic abscission of some organs that are normally not shed in Arabidopsis [68,69,71].

IDA signaling peptides are mostly known for their role in floral organ abscission [7] but, recently, a new function has been assigned to the IDA-HAE/HSL2 signaling module, namely a contribution to facilitate the passage of Lateral Root Primordia (LRP) through the main root and to assist in the Lateral Root (LR) emergence. In roots, IDA is strongly and continuously induced by auxin, whereas the hormone only transiently upregulates HAE and HSL2. Auxin induction of IDA depends on the auxin influx carrier LIKE AUX1-3 (LAX3) and the AUXIN RESPONSIVE FACTOR7 (ARF7). Auxin, originating from the tip of the primordium, coordinates cell separation in overlaying LRP tissues through signaling mediated by the IDA peptide. IDA and HAE have been shown to regulate LR emergence by promoting the degradation of the cell wall in the tissue layers overlaying the LRP as it grows outward [71] (Figure 3).

\section{Epidermal Patterning Factor/ EFP-Like (EPF/EPFL)}

Stomatal development relies on asymmetric cell divisions that are precisely coordinated in time and space through cell-to-cell communication networks. Stomata are usually separated from neighboring stomata by at least one cell, following the so-called "onecell-spacing rule". In this context as well, signaling peptides have a significant impact on development [44,72-74]. Multiple cysteine-rich signaling peptides that belong to the EPF family, in particular EPF1, EPF2, EPF-LIKE6/CHALLAH (EPFL6/CHAL) and EPFL9/ STOMAGEN, are associated with the regulation of stomatal density and positioning $[18,19,44,72,75-78]$. Overexpression of EPF1 and
EPF2 reduces stomatal density. Signaling depending on EPF1 and EPF2 requires the activity of the LRR-receptor-like protein TOO MANY MOUTHS (TMM) and the LRR-RLKs, ERECTA (ER) and ERECTA-LIKE1 (ERL1). EPF1 and EPF2 bind to the ER and ERL1 receptors and EPF2 to TMM. As TMM lacks an intracellular domain [79], another protein with an extracellular domain is required to mediate the signal transduction. Therefore, TMM interacts directly with the ER receptor and forms a complex that initiates the EPF signaling pathway $[18,19,78]$ (Figure 2).

Interestingly EPFL9/STOMAGEN, another member of the EPF family, acts antagonistically to EPF1 and EPF2 in stomatal development. EPFL9/STOMAGEN also requires TMM but, in this case, to positively control stomata formation, indicating that peptide hormones from the same family can have opposite functions through the same receptor in planta [20,80]. Lastly, the EPFL6/CHAL also negatively controls stomatal development in the epidermis of stems and hypocotyls. The ER receptors have been proposed to be involved in the transmission of the EPFL6/CHAL signal $[44,75,77]$.

Recently, a function distinct from stomatal development has been assigned to the signaling module EPF4/EPF6-ER/ERL [81]. EPF4 and EPF6 may be secreted from the endodermis and perceived by ER/ ERL1 in the phloem to regulate vascular development [82].

\section{Golven/Root Growth Factor/ CLE-Like (GLV/RGF/ CLEL)}

Three independent in silico studies identified a novel signaling peptide family that was designated GOLVEN (GLV), Root Growth Factor (RGF), or CLE-Like (CLEL). As the three research groups used different sequence homology parameters, not all the family members were initially identified by all groups. Overall, the GLV/RGF/CLEL gene family counts 11 members in Arabidopsis [9,10,22]. Although GLV/RGF genes had originally been detected in Arabidopsis they are conserved in all higher plants analyzed so far [10]. Like most other secreted signaling peptides, they code for posttranslationally modified small peptides. The GLV precursor proteins exhibit a typical tripartite structure [83]. The sequence of the native secreted peptide has been dissected for four family members, namely GLV1/RGF6, GLV2/RGF9, GLV3/RGF4 and GLV11/RGF1, which are 14, 15, 18 and 13 amino acids in length, respectively, and carry at least two types of posttranslational modifications in their mature form: tyrosine sulfation and proline hydroxylation. Tyrosine sulfation increases the bioactivity of the mature peptide, but hydroxylation of the proline residue has not been associated with any functional role so far $[9,10]$.

Collectively, the $G L V / R G F$ genes are transcribed in all plant organs, in both vegetative and reproductive stages. Nevertheless, individual transcription patterns are highly specific and are restricted to a few cells or cell types. The first loss-of-function phenotype reported for $G L V$ genes was a short-root phenotype that was also been observed in the tpst 1 mutant [9]. TPST is the only identified enzyme that catalyzes tyrosine sulfation in Arabidopsis [25]. The tpst short-root phenotype could not be complemented by the addition of the known tyrosinesulfated signaling peptides, PSKs and PLANT PEPTIDE CONTAINING SULFATED TYROSINE1 (PSY1). This observation implied that distinct tyrosine sulfated signaling peptides in Arabidopsis were involved in the positive regulation of root growth and lead to the discovery of the RGF peptide family $[9,84]$. Although single $r g f 1 / g l_{V} 11, r g f 2 / g l_{V} 5$, and $r g f 3 / g l_{V} 7$ loss-of-function mutants did not exhibit any obvious root phenotype, the $r g f 1$ rgf 2 rgf3 triple 
Page 7 of 11

mutant plants have short roots with a decreased number of meristematic cortical cells. Addition of a RGF1/GLV11 synthetic peptide in the growth medium restored the meristem size of both the tpst and $r g f 1$ rgf 2 rgf 3 mutants. GLV/RGF peptides coordinate the postembryonic maintenance of the root meristem cell niche through defined mRNA and protein levels of the PLETHORA (PLT) transcription factors [9] (Figure 3). However, overexpression and exogenous application of all GLV peptides had not the same effect on root growth, suggesting that not all members of the family are involved in root meristem maintenance $[9,10,46]$ (Figure 3).

All $G L V / R G F$ genes, except $G L V 1 / R G F 6$, are transcribed during LR development. Furthermore, overexpression of some $G L V$ genes strongly decrease the number of emerged LRs and treatment with some GLV/RGF synthetic peptides has similar effects on wild-type plants. Despite the lack of information on the LR phenotype in $G L V / R G F$ loss-of-function mutants, accumulating evidence suggests the involvement of the $G L V / R G F$ genes in LR initiation and development $[22,46]$.

A striking curly root phenotype resulting from overexpression of the $G L V / R G F$ genes revealed a novel function that differed from root growth regulation. Referring to this phenotype, Whitford et al. [10] designated this family GOLVEN (GLV), which means 'waves' in Dutch because the overexpression plants do not form the regular wavy-shaped roots normally observed when grown on the surface of impenetrable inclined agar medium. This observation suggested a possible role for the $G L V / R G F$ genes in gravitropic responses. Moreover, rotation of vertically grown $G L V 3 / R G F 4$ gain- or loss-offunction mutant seedlings revealed that the root response to gravistimulation was affected in both cases. GLV3/RGF4 gain-offunction plants display partially agravitropic roots, whereas the gravitropic response of amiRglv3 seedlings was enhanced. Addition of the corresponding synthetic peptide mimicked the gain-of-function phenotype. Plants overexpressing the GLV1/RGF6, GLV2/RGF9 or $G L V 3 / R G F 4$ genes have hypocotyls with an altered gravitropic phenotype reminiscent of the root gain-of-function phenotype.

The phenotype observed in GLV/RGF-overexpressing roots resembles that of mutants affected in either auxin response or transport. Further analysis pointed out that GLV3/RGF4 is involved in the root gravitropic response by influencing PIN-FORMED 2 (PIN2) trafficking. Differential turnover of the auxin efflux carrier PIN2 between the upper and lower side of the gravistimulated root mediates the formation of the lateral auxin gradients by which plants can respond to gravity [85]. Overexpression or treatment with GLV/RGF peptides hampers PIN2 trafficking in the root tip, hence preventing the proper formation or maintenance of the required auxin gradient. Most likely, a regulatory mechanism involving the GLV/RGF signal increases the robustness of the established auxin gradient. However, the molecular mechanism by which the signal controls PIN2 trafficking is still unknown [10].

Contrarily to the other Arabidopsis GLV genes, GLV4/RGF7 and $G L V 8$ are not expressed in the root tips and are thus expected to be involved in other root developmental process(es) than root meristem homeostasis and LR development. The ectopic overexpression of $G L V \&$ caused the production of root hairs with more complex and irregular shapes, whereas the glv 8 loss-of-function mutant harbors shorter root hairs with a simpler structure than the wild type. $G L V 4 / R G F$ silencing also resulted in root hairs that were shorter than those of the wild type, confirming the possible role of these $G L V / R G F$ genes in root hair development [46] (Figure 3).

\section{Phytosulfokines (PSK) and Plant Peptide Containing Sulfated Tyrosine (PSY) sulfated peptides}

As mentioned above, TPST is responsible for tyrosine sulfation in Arabidopsis, tpst knockout mutants display severe root and shoot phenotypes, and several sulfated peptides are known to be involved in root growth and regulation, in addition to GLV/RGF/CLEL. PSK- $a$ and $P S Y 1$ are thought to control root growth positively by promoting the mature cell size $[9,45,86,87]$.

The sulfated signaling peptide, PSK- $\alpha$ positively regulates cell expansion and hypocotyl length in Arabidopsis. Through the PSKR1 receptor, the PSK- $\alpha$ signal promotes hypocotyl elongation and protoplast expansion. tpst knockout mutants displayed severe phenotypes, including shortening of the hypocotyl that was only partially restored by supplementing the PSK- $\alpha$ peptide. This observation implies that, besides PSK- $\alpha$, likely one or more additional sulfated peptides contribute to the regulation of hypocotyl elongation [88].

Finally, a separate signaling pathway has been proposed recently that controls the division rate of the QC cells via PSK5 [89]. In this pathway, the transcription factor ETHYLENE RESPONSIVE FACTOR 115 (ERF115) binds to the promoter region of PSK5, thereby activating its expression. Upstream, brassinosteroids positively regulate ERF115-PSK5, whereas the CELL CYCLE SWITCH 52A2 subunit of the ANAPHASE-PROMOTING COMPLEX/ CYCLOSOME (ACP/CCS52A2 $)$ reduces ERF115 abundance through proteolysis [89] (Figure 3).

\section{Rapid Alkalinization Factor (RALF)}

A RALF peptide was first isolated from tobacco leaves as a molecule that triggers fast and strong $\mathrm{pH}$ hikes in tobacco suspension cell cultures, that stimulates a mitogen-activated protein kinase (MAPK), and that arrests root growth [6]. The cysteine-rich RALF-coding genes are found throughout the plant kingdom and Arabidopsis counts 34 $R A L F$ homologues [39]. The RALF and RALF-like (RAFL) genes are expressed in most tissues including roots, shoots, leaves and flowers, and are suspected to regulate diverse developmental modules, including root development $[6,90]$. Similar to most of the signaling peptides, RALFs possess a $\mathrm{N}$-terminal signal peptide indicating they are secreted [6] and conserved dibasic sites that could be targeted for subtilase proteolysis to generate the mature peptides.

AtRALF23 is downregulated by Brassinosteroids (BR) and is thought to be a negative regulator of BR-mediated growth-promoting effects [91, 92]. AtRALF23 overproduction phenotypes - dwarf bushy plants - were shown to be suppressed in the sbt6.1 subtilase null mutant background and no processed AtRALF23 peptide could be detected in these plants [93]. The plant-purified AtSBT6.1 proteolytic enzyme was demonstrated to process the AtRALF23 in vitro, thereby confirming that the propeptide is a direct target of the subtilase [93].

\section{C-Terminally Encoded Peptide (CEP)}

Small posttranslationally modified CEP peptides display diverse functions in various plant tissues $[23,29]$. Synthetic CEP1 peptide treatment, as well as $C E P$ gene overexpression, resulted in root growth inhibition through repression of meristematic cell division and expansion of the cells in the elongation zone, without interfering with the QC specification. Surprisingly, CEPI expression was not detected in the RAM, suggesting a nonspecific function of CEP1 in RAM 
development. In addition, $C E P 1$ is expressed in lateral root primordia, implying a yet to be defined role of CEP1 in lateral root development [29]. Finally CEP5 may be involved in shoot development but further research is required to identify its precise mode of action [23].

\section{Embryo Surrounding Factor1 (EFS1)}

An additional cysteine rich signaling peptide family was identified in a recent study that regulates early embryo patterning in flowering plants. EMBRYO SURROUNDING FACTOR1 (EFS1) is derived from the central cell gametes before fertilization and from micropylar embryo-surrounding endosperm cells after fertilization. It regulates the apical-basal development of the neighboring embryo through the receptor-like kinase SHORT SUSPENSOR and the mitogen-activated protein kinase YODA [94].

\section{Conclusions and Perspectives}

In the complete genome sequence of Arabidopsis, more than 1,000 genes have been found that encode putative secreted peptides with a potential signaling function $[29,40]$. In accordance to these studies, new signaling peptides are being identified and assigned to different plant growth and developmental functions, potentially leading to the discovery of unsuspected developmental programs. In parallel, as more information accrues about signaling peptides, additional structural hallmarks will likely result in the identification of new families.

Many aspects remain still to be elucidated concerning signaling peptides in plants. First, little is known about the details of their biosynthesis. Only a few proteases involved in the processing of the precursors have been reported so far $[92,93,95]$ and, to date, a general picture cannot be drawn that explains how the mature peptides are produced in plant tissues. Their small size has hampered their intracellular localization and the route from the initial translation of the precursor to the secretion of the mature peptide is still largely hypothetical. Future work should be oriented towards a better understanding of the mechanisms through which they are produced.

Signaling peptides control diverse processes related to plant physiology, growth, and development. However, we are just starting to uncover the pathways that they trigger. In most cases, the receptors they bind to and the downstream targets are unknown. Ongoing forward and reverse genetic screens will certainly provide some insights on these in the near future. Alternatively, the characterization of changes in the phosphorylation status or the structure of receptors upon binding with their peptide ligand will also yield valuable information. For example, the crystal structure of the flagellinsensitive 2 (FLS2) and BRASSINOSTEROID INSENSITIVE 1associated kinase 1 (BAK1) ectodomains was recently resolved as a complex with the bacterial flagellin fragment peptide, flg22 [96].

Finally, another level of complexity has to be taken into consideration. Converging evidence indicates that the signaling peptide and phytohormone pathways are interconnected [10,66,97]. Future studies will have to dissect the cross-talks so we better understand how these molecular signals interact to deliver the messages necessary to shape the plant.

\section{Acknowledgements}

Work in the lab of T.B. was in part financed by grants of the Interuniversity Attraction Poles Programme from the Belgian Federal
Science Policy Office, the Research Foundation Flanders (FWO) and by the special research fund of University Ghent.

\section{References}

1. Lindsey K, Casson S, Chilley P (2002) Peptides: new signalling molecules in plants. Trends Plant Sci 7: 78-83.

2. Vanstraelen M, Benková E (2012) Hormonal interactions in the regulation of plant development. Annu Rev Cell Dev Biol 28: 463-487.

3. Van Norman JM, Breakfield NW, Benfey PN (2011) Intercellular communication during plant development. Plant Cell 23: 855-864.

4. Murphy E, Smith S, De Smet I (2012) Small signaling peptides in Arabidopsis development: how cells communicate over a short distance. Plant Cell 24: 3198-3217.

5. Fletcher JC, Brand U, Running MP, Simon R, Meyerowitz EM (1999) Signaling of cell fate decisions by CLAVATA3 in Arabidopsis shoot meristems. Science 283: 1911-1914.

6. Pearce G, Moura DS, Stratmann J, Ryan CA Jr (2001) RALF, a 5-kDa ubiquitous polypeptide in plants, arrests root growth and development. Proc Natl Acad Sci U S A 98: 12843-12847.

7. Butenko MA, Patterson SE, Grini PE, Stenvik GE, Amundsen SS, et al. (2003) Inflorescence deficient in abscission controls floral organ abscission in Arabidopsis and identifies a novel family of putative ligands in plants. Plant Cell 15: 2296-2307.

8. Amano Y, Tsubouchi H, Shinohara H, Ogawa M, Matsubayashi Y (2007) Tyrosine-sulfated glycopeptide involved in cellular proliferation and expansion in Arabidopsis. Proc Natl Acad Sci U S A 104: 18333-18338.

9. Matsuzaki Y, Ogawa-Ohnishi M, Mori A, Matsubayashi Y (2010) Secreted peptide signals required for maintenance of root stem cell niche in Arabidopsis. Science 329: 1065-1067.

10. Whitford R, Fernandez A, Tejos R, Perez AC, Kleine-Vehn J, et al. (2012) GOLVEN secretory peptides regulate auxin carrier turnover during plant gravitropic responses. Dev Cell 22: 678-685.

11. Pearce G, Strydom D, Johnson S, Ryan CA (1991) A polypeptide from tomato leaves induces wound-inducible proteinase inhibitor proteins. Science 253: 895-897.

12. Hook V, Funkelstein L, Lu D, Bark S, Wegrzyn J, et al. (2008) Proteases for processing proneuropeptides into peptide neurotransmitters and hormones. Annu Rev Pharmacol Toxicol 48: 393-423.

13. Matsubayashi Y (2011) Post-translational modifications in secreted peptide hormones in plants. Plant Cell Physiol 52: 5-13.

14. Silverstein KA, Moskal WA Jr, Wu HC, Underwood BA, Graham MA, et al. (2007) Small cysteine-rich peptides resembling antimicrobial peptides have been under-predicted in plants. Plant J 51: 262-280.

15. Schopfer CR, Nasrallah ME, Nasrallah JB (1999) The male determinant of self-incompatibility in Brassica. Science 286: 1697-1700.

16. Takayama S, Shiba H, Iwano M, Shimosato H, Che FS, et al. (2000) The pollen determinant of self-incompatibility in Brassica campestris. Proc Natl Acad Sci U S A 97: 1920-1925.

17. Okuda S, Tsutsui H, Shiina K, Sprunck S, Takeuchi H, et al. (2009) Defensin-like polypeptide LUREs are pollen tube attractants secreted from synergid cells. Nature 458: 357-361.

18. Hara K, Kajita R, Torii KU, Bergmann DC, Kakimoto T (2007) The secretory peptide gene EPF1 enforces the stomatal one-cell-spacing rule. Genes Dev 21: 1720-1725.

19. Hara K, Yokoo T, Kajita R, Onishi T, Yahata S, et al. (2009) Epidermal cell density is autoregulated via a secretory peptide, EPIDERMAL PATTERNING FACTOR 2 in Arabidopsis leaves. Plant Cell Physiol 50: 1019-1031.

20. Kondo T, Kajita R, Miyazaki A, Hokoyama M, Nakamura-Miura T, et al. (2010) Stomatal density is controlled by a mesophyll-derived signaling molecule. Plant Cell Physiol 51: 1-8.

21. van de Sande K, Pawlowski K, Czaja I, Wieneke U, Schell J, et al. (1996) Modification of phytohormone response by a peptide encoded by ENOD40 of legumes and a nonlegume. Science 273: 370-373. 
22. Meng L, Buchanan BB, Feldman LJ, Luan S (2012) CLE-like (CLEL) peptides control the pattern of root growth and lateral root development in Arabidopsis. Proc Natl Acad Sci U S A 109: 1760-1765.

23. Roberts I, Smith S, De Rybel B, Van Den Broeke J, Smet W, et al. (2013) The CEP family in land plants: evolutionary analyses, expression studies, and role in Arabidopsis shoot development. J Exp Bot 64: 5371-5381.

24. Matsubayashi Y, Sakagami Y (1996) Phytosulfokine, sulfated peptides that induce the proliferation of single mesophyll cells of Asparagus officinalis L. Proc Natl Acad Sci U S A 93: 7623-7627.

25. Komori R, Amano Y, Ogawa-Ohnishi M, Matsubayashi Y (2009) Identification of tyrosylprotein sulfotransferase in Arabidopsis. Proc Natl Acad Sci U S A 106: 15067-15072.

26. Pearce G, Moura DS, Stratmann J, Ryan CA (2001) Production of multiple plant hormones from a single polyprotein precursor. Nature 411: 817-820.

27. Ito Y, Nakanomyo I, Motose H, Iwamoto K, Sawa S, et al. (2006) DodecaCLE peptides as suppressors of plant stem cell differentiation. Science 313: 842-845.

28. Kondo T, Sawa S, Kinoshita A, Mizuno S, Kakimoto T, et al. (2006) A plant peptide encoded by CLV3 identified by in situ MALDI-TOF MS analysis. Science 313: 845-848.

29. Ohyama K, Ogawa M, Matsubayashi Y (2008) Identification of a biologically active, small, secreted peptide in Arabidopsis by in silico gene screening, followed by LC-MS-based structure analysis. Plant J 55: 152-160.

30. Ohyama K, Shinohara H, Ogawa-Ohnishi M, Matsubayashi Y (2009) A glycopeptide regulating stem cell fate in Arabidopsis thaliana. Nat Chem Biol 5: 578-580.

31. Myllyharju J (2003) Prolyl 4-hydroxylases, the key enzymes of collagen biosynthesis. Matrix Biol 22: 15-24.

32. Lamport DTA (1967) Hydroxyproline-O-glycosidic Linkage of the Plant Cell Wall Glycoprotein Extensin. Nature 216: 1322-1324.

33. Ogawa-Ohnishi M, Matsushita W, Matsubayashi Y (2013) Identification of three hydroxyproline O-arabinosyltransferases in Arabidopsis thaliana. Nat Chem Biol 9: 726-730.

34. Seitz O (2000) Glycopeptide synthesis and the effects of glycosylation on protein structure and activity. Chembiochem 1:214-246.

35. Shinohara H, Matsubayashi Y (2013) Chemical synthesis of Arabidopsis CLV3 glycopeptide reveals the impact of hydroxyproline arabinosylation on peptide conformation and activity. Plant Cell Physiol 54: 369-374.

36. Matsubayashi Y (2011) Small post-translationally modified Peptide signals in Arabidopsis. Arabidopsis Book 9: e0150.

37. Petersen TN, Brunak S, von Heijne G, Nielsen H (2011) SignalP 4.0: discriminating signal peptides from transmembrane regions. Nat Methods 8: 785-786.

38. Stahl Y, Simon R (2012) Peptides and receptors controlling root development. Philos Trans R Soc Lond B Biol Sci 367: 1453-1460.

39. Olsen AN, Mundy J, Skriver K (2002) Peptomics, identification of novel cationic Arabidopsis peptides with conserved sequence motifs. In Silico Biol 2: 441-451.

40. Lease KA, Walker JC (2006) The Arabidopsis unannotated secreted peptide database, a resource for plant peptidomics. Plant Physiol 142: 831-838.

41. Clark SE, Running MP, Meyerowitz EM (1995) CLAVATA3 is a specific regulator of shoot and floral meristem development affecting the same processes as CLAVATA1 Development 121: 2057-2067.

42. Yang SL, Xie LF, Mao HZ, Puah CS, Yang WC, et al. (2003) Tapetum determinant1 is required for cell specialization in the Arabidopsis anther. Plant Cell 15: 2792-2804.

43. Wang G, Fiers M (2010) CLE peptide signaling during plant development. Protoplasma 240: 33-43.

44. Shimada T, Sugano SS, Hara-Nishimura I (2011) Positive and negative peptide signals control stomatal density. Cell Mol Life Sci 68: 2081-2088.

45. Yamada M, Sawa S (2013) The roles of peptide hormones during plant root development. Curr Opin Plant Biol 16: 56-61.
46. Fernandez A, Drozdzecki A, Hoogewijs K, Nguyen A, Beeckman T, et al. (2013) Transcriptional and functional classification of the GOLVEN/ ROOT GROWTH FACTOR/CLE-like signaling peptides reveals their role in lateral root and hair formation. Plant Physiol 161: 954-970.

47. Jun J, Fiume E, Roeder AH, Meng L, Sharma VK, et al. (2010) Comprehensive analysis of CLE polypeptide signaling gene expression and overexpression activity in Arabidopsis. Plant Physiol 154: 1721-1736.

48. Brand U, Fletcher JC, Hobe M, Meyerowitz EM, Simon R (2000) Dependence of stem cell fate in Arabidopsis on a feedback loop regulated by CLV3 activity. Science 289: 617-619.

49. Mayer KF, Schoof H, Haecker A, Lenhard M, Jürgens G, et al. (1998) Role of WUSCHEL in regulating stem cell fate in the Arabidopsis shoot meristem. Cell 95: 805-815.

50. Schoof H, Lenhard M, Haecker A, Mayer KF, Jürgens G, et al. (2000) The stem cell population of Arabidopsis shoot meristems in maintained by a regulatory loop between the CLAVATA and WUSCHEL genes. Cell 100: 635-644.

51. Katsir L, Davies KA, Bergmann DC, Laux T (2011) Peptide signaling in plant development. Curr Biol 21: R356-364.

52. Yadav RK, Perales M, Gruel J, Girke T, Jönsson H, et al. (2011) WUSCHEL protein movement mediates stem cell homeostasis in the Arabidopsis shoot apex. Genes Dev 25: 2025-2030.

53. Müller R, Bleckmann A, Simon R (2008) The receptor kinase CORYNE of Arabidopsis transmits the stem cell-limiting signal CLAVATA3 independently of CLAVATA1. Plant Cell 20: 934-946.

54. Nimchuk ZL, Tarr PT, Ohno C, Qu X, Meyerowitz EM (2011) Plant stem cell signaling involves ligand-dependent trafficking of the CLAVATA1 receptor kinase. Curr Biol 21: 345-352.

55. Bommert P, Je BI, Goldshmidt A, Jackson D (2013) The maize GÎ \pm gene COMPACT PLANT2 functions in CLAVATA signalling to control shoot meristem size. Nature 502: 555-558.

56. Hobe M, Müller R, Grünewald M, Brand U, Simon R (2003) Loss of CLE40, a protein functionally equivalent to the stem cell restricting signal CLV3, enhances root waving in Arabidopsis. Dev Genes Evol 213: 371-381.

57. Stahl Y, Wink RH, Ingram GC, Simon R (2009) A signaling module controlling the stem cell niche in Arabidopsis root meristems. Curr Biol 19: 909-914.

58. Stahl Y, Grabowski S, Bleckmann A, Kühnemuth R, Weidtkamp-Peters S, et al. (2013) Moderation of Arabidopsis root stemness by CLAVATA1 and ARABIDOPSIS CRINKLY4 receptor kinase complexes. Curr Biol 23: 362-371.

59. Fukuda H, Komamine A (1980) Establishment of an Experimental System for the Study of Tracheary Element Differentiation from Single Cells Isolated from the Mesophyll of Zinnia elegans. Plant Physiol 65: 57-60.

60. Hirakawa Y, Shinohara H, Kondo Y, Inoue A, Nakanomyo I, et al. (2008) Non-cell-autonomous control of vascular stem cell fate by a CLE peptide/ receptor system. Proc Natl Acad Sci U S A 105: 15208-15213.

61. Whitford R, Fernandez A, De Groodt R, Ortega E, Hilson P (2008) Plant CLE peptides from two distinct functional classes synergistically induce division of vascular cells. Proc Natl Acad Sci U S A 105: 18625-18630.

62. Hirakawa Y, Kondo Y, Fukuda H (2011) Establishment and maintenance of vascular cell communities through local signaling. Curr Opin Plant Biol 14: 17-23.

63. Etchells JP, Turner SR (2010) The PXY-CLE41 receptor ligand pair defines a multifunctional pathway that controls the rate and orientation of vascular cell division. Development 137: 767-774.

64. Hirakawa Y, Kondo Y, Fukuda H (2010) TDIF peptide signaling regulates vascular stem cell proliferation via the WOX4 homeobox gene in Arabidopsis. Plant Cell 22: 2618-2629.

65. Suer S, Agusti J, Sanchez P, Schwarz M, Greb T (2011) WOX4 imparts auxin responsiveness to cambium cells in Arabidopsis. Plant Cell 23: 3247-3259. 
66. Kondo Y, Hirakawa Y, Kieber JJ, Fukuda H (2011) CLE peptides can negatively regulate protoxylem vessel formation via cytokinin signaling. Plant Cell Physiol 52: 37-48.

67. Depuydt S, Rodriguez-Villalon A, Santuari L, Wyser-Rmili C, Ragni L, et al. (2013) Suppression of Arabidopsis protophloem differentiation and root meristem growth by CLE45 requires the receptor-like kinase BAM3. Proc Natl Acad Sci U S A 110: 7074-7079.

68. Jinn TL, Stone JM, Walker JC (2000) HAESA, an Arabidopsis leucinerich repeat receptor kinase, controls floral organ abscission. Genes Dev 14: 108-117.

69. Stenvik GE, Butenko MA, Urbanowicz BR, Rose JK, Aalen RB (2006) Overexpression of INFLORESCENCE DEFICIENT IN ABSCISSION activates cell separation in vestigial abscission zones in Arabidopsis. Plant Cell 18: 1467-1476.

70. Stenvik GE, Tandstad NM, Guo Y, Shi CL, Kristiansen W, et al. (2008) The EPIP peptide of INFLORESCENCE DEFICIENT IN ABSCISSION is sufficient to induce abscission in arabidopsis through the receptor-like kinases HAESA and HAESA-LIKE2. Plant Cell 20: 1805-1817.

71. Kumpf RP, Shi CL, Larrieu A, Stø IM, Butenko MA, et al. (2013) Floral organ abscission peptide IDA and its HAE/HSL2 receptors control cell separation during lateral root emergence. Proc Natl Acad Sci U S A 110: 5235-5240.

72. Hunt L, Gray JE (2009) The signaling peptide EPF2 controls asymmetric cell divisions during stomatal development. Curr Biol 19: 864-869.

73. Hunt L, Bailey KJ, Gray JE (2010) The signalling peptide EPFL9 is a positive regulator of stomatal development. New Phytol 186: 609-614.

74. Rowe MH, Bergmann DC (2010) Complex signals for simple cells: the expanding ranks of signals and receptors guiding stomatal development. Curr Opin Plant Biol 13: 548-555.

75. Abrash EB, Bergmann DC (2010) Regional specification of stomatal production by the putative ligand CHALLAH. Development 137: 447-455.

76. Abrash EB, Davies KA, Bergmann DC (2011) Generation of signaling specificity in Arabidopsis by spatially restricted buffering of ligandreceptor interactions. Plant Cell 23: 2864-2879.

77. Ohki S, Takeuchi M, Mori M (2011) The NMR structure of stomagen reveals the basis of stomatal density regulation by plant peptide hormones. Nat Commun 2: 512.

78. Lee JS, Kuroha T, Hnilova M, Khatayevich D, Kanaoka MM, et al. (2012) Direct interaction of ligand-receptor pairs specifying stomatal patterning. Genes Dev 26: 126-136.

79. Shpak ED, McAbee JM, Pillitteri LJ, Torii KU (2005) Stomatal patterning and differentiation by synergistic interactions of receptor kinases. Science 309: 290-293.

80. Sugano SS, Shimada T, Imai Y, Okawa K, Tamai A, et al. (2010) Stomagen positively regulates stomatal density in Arabidopsis. Nature 463: 241-244.

81. Uchida N, Lee JS, Horst RJ, Lai HH, Kajita R, et al. (2012) Regulation of inflorescence architecture by intertissue layer ligand-receptor communication between endodermis and phloem. Proc Natl Acad Sci U S A 109: 6337-6342.

82. Uchida N, Tasaka M (2013) Regulation of plant vascular stem cells by endodermis-derived EPFL-family peptide hormones and phloemexpressed ERECTA-family receptor kinases. J Exp Bot 64: 5335-5343.

83. Fernandez A, Hilson P, Beeckman T (2013) GOLVEN peptides as important regulatory signalling molecules of plant development. J Exp Bot 64: 5263-5268.

84. Zhou W, Wei L, Xu J, Zhai Q, Jiang H, et al. (2010) Arabidopsis Tyrosylprotein sulfotransferase acts in the auxin/PLETHORA pathway in regulating postembryonic maintenance of the root stem cell niche. Plant Cell 22: 3692-3709.

85. Vanneste S, Friml J (2009) Auxin: a trigger for change in plant development. Cell 136: 1005-1016.

86. Matsubayashi Y, Ogawa M, Kihara H, Niwa M, Sakagami Y (2006) Disruption and overexpression of Arabidopsis phytosulfokine receptor gene affects cellular longevity and potential for growth. Plant Physiol 142: 45-53.

87. Kutschmar A, Rzewuski G, Stührwohldt N, Beemster GT, Inzé D, et al. (2009) PSK-Î士 promotes root growth in Arabidopsis. New Phytol 181: 820-831.

88. Stührwohldt N, Dahlke RI, Steffens B, Johnson A, Sauter M (2011) Phytosulfokine-Î̀ controls hypocotyl length and cell expansion in Arabidopsis thaliana through phytosulfokine receptor 1. PLoS One 6: e21054.

89. Heyman J, Cools T, Vandenbussche F, Heyndrickx KS, Van Leene J, et al. (2013) ERF115 controls root quiescent center cell division and stem cell replenishment. Science 342: 860-863.

90. Wu J, Kurten EL, Monshausen G, Hummel GM, Gilroy S, et al. (2007) NaRALF, a peptide signal essential for the regulation of root hair tip apoplastic $\mathrm{pH}$ in Nicotiana attenuata, is required for root hair development and plant growth in native soils. Plant J 52: 877-890.

91. Nemhauser JL, Mockler TC, Chory J (2004) Interdependency of brassinosteroid and auxin signaling in Arabidopsis. PLoS Biol 2: E258.

92. Srivastava R, Liu JX, Howell SH (2008) Proteolytic processing of a precursor protein for a growth-promoting peptide by a subtilisin serine protease in Arabidopsis. Plant J 56: 219-227.

93. Srivastava R, Liu JX, Guo H, Yin Y, Howell SH (2009) Regulation and processing of a plant peptide hormone, AtRALF23, in Arabidopsis. Plant J 59: 930-939.

94. Costa LM, Marshall E, Tesfaye M, Silverstein KA, Mori M, et al. (2014) Central cell-derived peptides regulate early embryo patterning in flowering plants. Science 344: 168-172.

95. Tamaki T, Betsuyaku S, Fujiwara M, Fukao Y, Fukuda H, et al. (2013) SUPPRESSOR OF LLP1 1-mediated C-terminal processing is critical for CLE19 peptide activity. Plant J 76: 970-981.

96. Sun Y, Li L, Macho AP, Han Z, Hu Z, et al. (2013) Structural basis for flg22-induced activation of the Arabidopsis FLS2-BAK1 immune complex. Science 342: 624-628.

97. Chilley PM, Casson SA, Tarkowski P, Hawkins N, Wang KL, et al. (2006) The POLARIS peptide of Arabidopsis regulates auxin transport and root growth via effects on ethylene signaling. Plant Cell 18: 3058-3072.

98. Cock JM, McCormick S (2001) A large family of genes that share homology with CLAVATA3. Plant Physiol 126: 939-942.

99. Fiers M, Ku KL, Liu CM (2007) CLE peptide ligands and their roles in establishing meristems. Curr Opin Plant Biol 10: 39-43.

100. Deyoung BJ, Clark SE (2008) BAM receptors regulate stem cell specification and organ development through complex interactions with CLAVATA signaling. Genetics 180: 895-904.

101. Kinoshita A, Betsuyaku S, Osakabe Y, Mizuno S, Nagawa S, et al. (2010) RPK2 is an essential receptor-like kinase that transmits the CLV3 signal in Arabidopsis. Development 137: 3911-3920.

102. Matsubayashi Y, Ogawa M, Morita A, Sakagami Y (2002) An LRR receptor kinase involved in perception of a peptide plant hormone, phytosulfokine. Science 296: 1470-1472.

103. Gehring CA, Irving HR (2003) Natriuretic peptides--a class of heterologous molecules in plants. Int J Biochem Cell Biol 35: 1318-1322.

104. Ludidi NN, Heazlewood JL, Seoighe C, Irving HR, Gehring CA (2002) Expansin-like molecules: novel functions derived from common domains. J Mol Evol 54: 587-594.

105. Rafudeen S, Gxaba G, Makgoke G, Bradley G, Pironcheva G, et al. (2003) A role for plant natriuretic peptide immuno-analogues in $\mathrm{NaCl}$ - and drought-stress responses. Physiologia Plantarum 119: 554-562.

106. Wang YH, Gehring C, Cahill DM, Irving HR (2007) Plant natriuretic peptide active site determination and effects on cGMP and cell volume regulation. Functional Plant Biol 34: 645-653.

107. Gottig N, Garavaglia BS, Daurelio LD, Valentine A, Gehring C, et al. (2008) Xanthomonas axonopodis pv. citri uses a plant natriuretic peptide-like protein to modify host homeostasis. Proc Natl Acad Sci U S A 105: 18631-18636. 
Citation: Ghorbani S, Fernandez A, Hilson P, Beeckman T (2014) Signaling Peptides in Plants. Cell Dev Biol 3: 141. doi:

Page 11 of 11

108. Ruzvidzo O, Donaldson L, Valentine A, Gehring C (2011) The Arabidopsis thaliana natriuretic peptide AtPNP-A is a systemic regulator of leaf dark respiration and signals via the phloem. J Plant Physiol 168: 1710-1714.

109. Wang YH, Gehring C, Irving HR (2011) Plant natriuretic peptides are apoplastic and paracrine stress response molecules. Plant Cell Physiol 52: 837-850.

110. Casson SA, Chilley PM, Topping JF, Evans IM, Souter MA, et al. (2002) The POLARIS gene of Arabidopsis encodes a predicted peptide required for correct root growth and leaf vascular patterning. Plant Cell 14: 1705-1721.

111. Huffaker A, Pearce G, Ryan CA (2006) An endogenous peptide signal in Arabidopsis activates components of the innate immune response. Proc Natl Acad Sci U S A 103: 10098-10103.

112. Yamaguchi Y, Pearce G, Ryan CA (2006) The cell surface leucine-rich repeat receptor for AtPep1, an endogenous peptide elicitor in Arabidopsis, is functional in transgenic tobacco cells. Proc Natl Acad Sci U S A 103: 10104-10109.

113. Pearce G, Yamaguchi Y, Munske G, Ryan CA (2008) Structure-activity studies of AtPep1, a plant peptide signal involved in the innate immune response. Peptides 29: 2083-2089.

114. Qi Z, Verma R, Gehring C, Yamaguchi Y, Zhao Y, et al. (2010) Ca2+ signaling by plant Arabidopsis thaliana Pep peptides depends on
AtPepR1, a receptor with guanylyl cyclase activity, and cGMP-activated Ca2+ channels. Proc Natl Acad Sci U S A 107: 21193-21198.

115. Haruta M, Sabat G, Stecker K, Minkoff BB, Sussman MR (2014) A peptide hormone and its receptor protein kinase regulate plant cell expansion. Science 343: 408-411.

116. Narita NN, Moore S, Horiguchi G, Kubo M, Demura T, et al. (2004) Overexpression of a novel small peptide ROTUNDIFOLIA4 decreases cell proliferation and alters leaf shape in Arabidopsis thaliana. Plant J 38: 699-713.

117. Wen J, Lease KA, Walker JC (2004) DVL, a novel class of small polypeptides: overexpression alters Arabidopsis development. Plant J 37: 668-677.

118. Ikeuchi M, Yamaguchi T, Kazama T, Ito T, Horiguchi G, et al. (2011) ROTUNDIFOLIA4 regulates cell proliferation along the body axis in Arabidopsis shoot. Plant Cell Physiol 52: 59-69.

119. Vanoosthuyse V, Miege C, Dumas C, Cock JM (2001) Two large Arabidopsis thaliana gene families are homologous to the Brassica gene superfamily that encodes pollen coat proteins and the male component of the self-incompatibility response. Plant Mol Biol 46: 17-34.

120. Jia G, Liu X, Owen HA, Zhao D (2008) Signaling of cell fate determination by the TPD1 small protein and EMS1 receptor kinase. Proc Natl Acad Sci U S A 105: 2220-2225. 